\title{
Assessment of Knowledge and Perception of Biological Medicines among Undergraduate Pharmacy Students in North India: A Multi-centric Study
}

\author{
Zeenat Iqbal' , Mohd. Aamir Mirza ${ }^{1 *}$, Mohammad Daud Ali² \\ 'Department of Pharmaceutics, School of Pharmaceutical Education and Research(SPER), Jamia Hamdard, Hamdard Nagar, New Delhi, INDIA \\ 2Department of Pharmacy, Mohammed Al-Mana College for Medical Sciences, Abdulrazaq Bin Hammam Street, As Safa, Dammam, SAUDI ARABIA.
}

\begin{abstract}
Objectives: In the current study, we have evaluated pharmacy undergraduate student's knowledge and perceptions towards this class of drug products. Methods: A random survey of 349 pharmacy students of six different pharmacy colleges from north India was carried out on an online-based questionnaire system to investigative knowledge and attitude towards biological/biosimilar. Chi-square test was used for the computation of $p$-value. Results: Out of 349 students, $80.22 \%$ of students have good knowledge about the same. $44.12 \%$ responded that the products are generally safe while $60.74 \%$ responded that these products don't produce any kind of adverse drug reaction. $62.18 \%$ students were not updated about ADR reporting system in India. But the students think that its knowledge is important but the educational training has been inadequate. Conclusion: Due to unawareness about biological products, there is a need to address
\end{abstract}

the knowledge gap in graduating pharmacy students. Lack of knowledge could be overcome by upgrading the curriculum or through professional development courses.

Key words: ADR (Adverse Drug reaction), Biosimilars, Perception, Pharmacy student.

Correspondence

Dr. Mohd. Aamir Mirza

Assistant Professor, Department of Pharmaceutics, School of Pharmaceutical Education and Research (SPER), Jamia Hamdard, New Delhi-62, INDIA.

Phone: +919213378765

Email: aamir.pharma@gmail.com

DOI: 10.5530/jyp.2020.12.34

\section{INTRODUCTION}

A biologic drug, in general, is also referred to as a "biopharmaceutical," "bio-drug," "biologic," or "biological." Biologics, whether reference or biosimilar, are produced using living cells through the exploration of biotechnology such as recombinant DNA technology, controlled gene expression, or antibody technologies ${ }^{1,2} \mathrm{~A}$ biosimilar is a biological product that is similar, but not identical, to a reference biological medicine and therefore, requires a separate marketing approval on patent expiration of the reference product. ${ }^{3}$ As per World Health Organization (WHO), biosimilars can be defined as a biological product that is formed by genetic engineering techniques and is "similar" in terms of quality, safety and efficacy to a reference biologic. "Biosimilar" is the term used in Europe and the U.S., "follow-on pharmaceuticals" in Japan, "subsequent entry biologics" in Canada and "bio-comparables" in Mexico. The inventive version of a biologic is referred to as the "innovator," or "reference" drug. Prior to approval, biosimilars are required to meet strict guidelines that warrant they are sufficiently equivalent to their reference biologic in terms of quality, safety and efficacy. ${ }^{5}$ In USA Biologics Price rivalry and Innovation Act of 2009 permits the FDA to oversee an "abbreviated pathway" for approval of biologics that are "biosimilar" to already sanctioned products. The abbreviated pathway is supposed to eradicate avoidable and unethical testing of biosimilars in animals and humans. Thus reducing time, money and manpower. The Patient Protection and Affordable Care Act of 2010 (USA) also supports this. The limitations with biosimilar are that the two biosimilars have a diverse origin, the two biosimilars may have similar therapeutic action, may have dissimilar side-effects and henceforth require comprehensive testing. ${ }^{6}$ The active protein structures of biological make them prone to boost acute and chronic immunogenic responses. ${ }^{7,8}$ Then again, the active ingredient in a drug formulation (i.e., chemical moiety based) is a single molecular structure and can readily be reproduced by chemical synthesis, but the same in biologic products may be a collection of outsized protein isoforms, thus making the production process additionally complex. ${ }^{2,3}$

The newest Guidelines of India "Draft Guidelines on Similar Biologics: Regulatory Necessities for Marketing Authorization in India" were publicized in June 2012, by the Department of Biotechnology (DBT). The guidelines address the pre-marketing and post-marketing regulatory obligation (i.e., "comparability exercise") and also address the necessities related to manufacturing procedures and quality control. The Indian guideline is in coherence with the biosimilar guidelines of USA and EU like India has embraced a "sequential approach" (like "stepwise approach" - US and EU) to market biosimilar products. ${ }^{9,10}$

The assessment committee on genetic manipulation of the Genetic Engineering Approval Committee (GEAC) with the permission of Drug Controller General of India (DCGI), approved clinical trials to be conducted in India allied to biosimilar therapeutic products. The biosimilar has to reveal comparable data of non-clinical studies such as pharmacokinetics and toxicology (safety pharmacology, reproduction toxicology, mutagenicity and carcinogenicity) and clinical studies (efficacy and tolerability for each indication) henceforth it gets approval for all indications of the reference medicine. ${ }^{11}$

The range of biosimilars products in India contain primarily vaccine, monoclonal antibodies, recombinant proteins and diagnostics, insulin (wosulin, insugen, recosulin), erythropoietin (epofit, epofer, wepox, ceriton, hemax), Hepatitis B vaccine (Bevac, Revac B, Enivac B, Biovac B, 
Genevac B, Shanvac B), granulocyte colony-stimulating factor (Neukine, G-CSF-Grastim,), streptokinase (STPase, indikinase, shankinase), interferon alpha-2B (shanferon), Rituxinab (MAb), epidermal growth factor receptor (anti-EGFR) (MAb)-(bioMAB-EGFR, reditux). ${ }^{12}$

Pharmacovigilance is also a key aspect for biosimilar drugs because these do not reference medicine as such and are from a different manufacturer. Many adverse effects may appear if a biosimilar drug is used more widely, for a longer period of time, in a larger number of populations. Both manufacturer and prescriber should be conscious of the importance of post-marketing vigilance and on patients using biosimilar. ${ }^{13,14}$ Thus it requires a precisely designed pharmacovigilance plan.

The primary objective of the study was to evaluate knowledge and perceptions of biological drugs among pharmacy students and to suggest ways to make them aware of the same.

\section{MATERIALS AND METHODS}

\section{Survey design}

A cross-sectional descriptive study was carried out among all year pharmacy students in the various universities/college in North India.

\section{Setting}

The survey was distributed via e-mail to the all year's pharmacy undergraduates in the Delhi Pharmaceutical Sciences and Research University (New Delhi), G.L.A. University (Mathura), Innovative College of Pharmacy (Greater Noida), Integral University (Lucknow), School of Pharmaceutical Education and Research, Jamia Hamdard (New Delhi) and other North Indian pharmacy colleges.

\section{Population}

The total study population was 349, 49 students from the Delhi Pharmaceutical Sciences and Research University, 63 from the G.L.A. University Mathura, 63 from the Innovative College of Pharmacy, 58 from the Integral University and 74 from the Jamia Hamdard and 42 from other colleges of pharmacy. All the eligible students were registered for the study hence the response rate was $100 \%$.

\section{Survey sample}

A questionnaire-based cross-sectional study was carried out. The study tool was a set of a self-administered questionnaires.

\section{Method}

The study instrument was a self-administered questionnaire. A pretested study questionnaire was used for data collection. This was a noninterventional, anonymized, self-administered, one-time web-based survey among undergraduate pharmacy students in north India. This survey was conducted over a period of 3 months, from December 2018 to February 2019.

\section{Survey procedure}

It was a closed survey. A request to distribute an invitation to participate in this web-based survey was emailed to all pharmacy students, those belonging to the above-mentioned universities and pharmacy colleges. The invitation letter included a link to the web survey. Reminder emails were sent via the professional overtones at two weeks afterward the first mailing. The first page of the survey includes information and recitation of the survey, asking for their voluntary contribution. By reading and responding, they shared their consent. The survey questionnaire was made in such a way that it could not be submitted until all questions had been answered.

\section{Survey questionnaire}

A questionnaire was developed from emerging themes on biological medicine. The survey used an electronic website (Survey Monkey). Questions were developed to investigate the knowledge and perception of biological. The survey was piloted on a small number of students and revised applicable to eliminate any redundancy/difficulty or ambiguous questions. The questionnaires didn't include any personal information.

\section{Statistical analysis}

The answers of the contributors were examined using SPSS version 20 (IBM, Chicago, IL). The suggestive analysis was used to pick the demographic information in rates and percentages. The variations between the two groups are compared with the use of the chi-square test. A $p$-value $<0.05$ was marked to be statistically relevant.

\section{RESULTS}

\section{Characterization of participants}

The response rate of the survey was $100 \%$. The demographic characteristics of respondents' are summarized in Table 1 . The mean age of the respondents was $20 \pm 2.41$ (years). Out of 349 participants, $218(62.46 \%)$ were male and $131(37.5 \%)$ were female. Out of the total 349 students who participated in this study, $14 \%$ were from the DPSRU followed by $16.61 \%$ from Integral University, $21.2 \%$ from Jamia Hamdard, $18.05 \%$ each from the G.L.A. University, Innovative College of pharmacy and remaining $12.03 \%$ from remaining pharmacy colleges. All the participants were students of different years of the pharmacy course $\left(1^{\text {st }}\right.$ to $\left.4^{\text {th }}\right)$. Among all the participants $23.2 \%$ from the first year, $21.77 \%$ from the second year, $26.07 \%$ from the third year and $28.93 \%$ students were from the fourth year. More than half of the participants were male $(\mathrm{N}=218,62.46 \%)$.

\section{Table 1: Demographic and background Characteristics of participants} ( $N=349$ ).

\begin{tabular}{ccc}
\hline Characteristics & Frequency (N) (\%) & $p$-Value \\
\hline Gender & $218(62.46)$ & $p<0.05$ \\
Male & $131(37.5)$ & \\
Female & & \\
Age (years) & $46(13.18)$ & $p<0.05$ \\
$16-18$ & $214(61.31)$ & \\
$19-21$ & $89(25.50)$ & \\
$22-24$ & & \\
Academic year & $81(23.2)$ & \\
$1^{\text {st }}$ Year & $76(21.77)$ & \\
$2^{\text {nd }}$ Year & $91(26.07)$ & \\
$3^{\text {rd }}$ Year & $101(28.93)$ & \\
$4^{\text {th }}$ Year & & \\
Institute name & $49(14.04)$ & \\
U-1 & $63(18.05)$ & \\
U-2 & $63(18.05)$ & \\
U-3 & $58(16.61)$ & \\
U-4 & $74(21.2)$ & \\
U-5 & $42(12.03)$ & \\
U-6 &
\end{tabular}

U-1=DPSRU, U-2=G.L.A. University, U-3=Innovative college of pharmacy, U4=Integral University, U-5=Jamia Hamadard, U-6= Others

$P$-Value Calculated with chi-square test.

$P$-Value $0 \leq 0.05$ consider as significant. 


\section{Knowledge about biologic/biosimilars medicines}

Table 2 describes the knowledge regarding biologics or biosimilar. Among all $280(80.22 \%, p<0.05)$ participants said that they were familiar with the biologics. $280(80.22 \%, p<0.05)$ participants were eager to know more information about biologic/biosimilars medicines. 195(55.87\%, $p=0.028)$ participants were assuming that biological medicines are not safe. Among all the participants, $212(60.74 \%, p<0.05)$ were of the view that biological medicines can't produce any adverse drug reaction. $217(62.18 \%, p<0.05)$ participated in pharmacy students had no idea about biological medicine's adverse drug reaction reporting system available in India. Among all participants $231(66.18 \%, p<0.05)$ had no idea about biological medicines/biosimilars drug approval process for marketing in India.

\section{Perception of biosimilars/biologic medicines}

We aimed to understand the participants' attitudes towards biological. Descriptive statistics of the pharmacy student's perceptions have been shown in Table 3. $277(79.36 \%, p<0.05)$ respondents highlighted that in current curricula with biological medicines/biosimilars should be taught in pharmacy school. Most of the participants 279 (79.94\%, $p<0.05)$ agree that biological medicines/biosimilars are an integral part of the field of patient care. $322(92.26 \%, p<0.05)$ Pharmacy students think that they must know about Biological medicines/biosimilars. An almost an equal number of participants $151(43.26 \%, p<0.05)$ have reliable sources of information on biological medicines/biosimilars while 153(43.55\%), $p<0.05$ given neutral response. A total of $247(70.77 \%, p<0.05)$ pharmacy students agree that biological medicines/biosimilars must be recommended in clinical practice. Out of 379 participants 129 (36.96\%, $p=0.233$ ) participants disagree that biological medicines/biosimilars are similar to herbal medicines like Ayurveda and Unani. 127 (36.38\%, $p<$ 0.05 ) students agree that biological medicines/biosimilars are better than herbal medicines like Ayurveda and Unani medicines.

\section{DISCUSSION}

We performed a cross-sectional descriptive assessment of knowledge and perception of pharmacy grad students about the biological in India. Our

Table 2: Knowledge of Biosimilars/biologic among pharmacy undergraduates in India.

\begin{tabular}{|c|c|c|c|}
\hline Statement & $\begin{array}{c}\text { Yes } \\
\text { Frequency } \\
(\%)\end{array}$ & $\begin{array}{l}\text { No Frequency } \\
\text { (\%) }\end{array}$ & *P-value \\
\hline Do you have knowledge about biosimilars/biologic medicines? & $280(80.22)$ & $69(19.77)$ & $p<0.05$ \\
\hline $\begin{array}{l}\text { I think it is necessary to get more information about biosimilars/ } \\
\text { biologic medicines }\end{array}$ & $338(96.84)$ & $11(3.15)$ & $p<0.05$ \\
\hline Are biological medicines/biosimilars safe? & $154(44.12)$ & 195(55.87) & 0.028 \\
\hline $\begin{array}{c}\text { Do biosimilars /biologic medicines produce any Adverse Drug } \\
\text { Reactions? }\end{array}$ & $137(39.25)$ & $212(60.74)$ & $p<0.05$ \\
\hline $\begin{array}{l}\text { Is biological medicines/biosimilars ADR } \\
\text { reporting system available in India? }\end{array}$ & $132(37.82)$ & $217(62.18)$ & $p<0.05$ \\
\hline $\begin{array}{c}\text { Do you know about biological medicines/biosimilars } \\
\text { drug approval process for marketing? }\end{array}$ & $118(33.81)$ & $231(66.18)$ & $p<0.05$ \\
\hline
\end{tabular}

${ }^{\star} P$-Value Calculated with chi-square test.

${ }^{*} P$ value $0 \leq 0.05$ consider as significant.

Table 3: Perception of biologic/biosimilars among pharmacy students.

\begin{tabular}{|c|c|c|c|c|}
\hline Statement & $\begin{array}{c}\text { Agree } \\
\text { Frequency } \\
\text { (\%) }\end{array}$ & $\begin{array}{c}\text { Disagree } \\
\text { Frequency } \\
\text { (\%) }\end{array}$ & $\begin{array}{l}\text { Neutral } \\
\text { Frequency } \\
\text { (\%) }\end{array}$ & ${ }^{*} p$-value \\
\hline $\begin{array}{c}\text { Biological medicines/biosimilars should be taught in } \\
\text { Pharmacy School }\end{array}$ & $277(79.36)$ & $8(2.29)$ & $64(18.33)$ & $p<0.05$ \\
\hline $\begin{array}{c}\text { Biological medicines/biosimilars are integral parts in the } \\
\text { field of patient care }\end{array}$ & $279(79.94)$ & $9(2.57)$ & $61(17.147)$ & $p<0.05$ \\
\hline $\begin{array}{c}\text { Pharmacy students must know Biological medicines/ } \\
\text { biosimilars }\end{array}$ & $322(92.26)$ & $6(1.71)$ & $21(6.01)$ & $p<0.05$ \\
\hline $\begin{array}{l}\text { I know reliable sources of information on Biological } \\
\text { medicines/biosimilars }\end{array}$ & 151(43.26) & $45(12.89)$ & $153(43.55)$ & $p<0.05$ \\
\hline $\begin{array}{l}\text { Pharmacy students must recommend Biological } \\
\text { medicines/biosimilars in their clinical practice }\end{array}$ & $247(70.77)$ & $19(5.44)$ & $83(23.78)$ & $p<0.05$ \\
\hline $\begin{array}{l}\text { Biological medicines/biosimilars are similar to herbal } \\
\text { medicines like Ayurveda and Unani medicines. }\end{array}$ & $117(33.52)$ & $129(36.96)$ & $103(29.51)$ & 0.233 \\
\hline $\begin{array}{l}\text { Biological medicines/biosimilars are better than herbal } \\
\text { medicines like Ayurveda and Unani medicines. }\end{array}$ & $127(36.38)$ & $72(20.63)$ & $150(42.97)$ & $p<0.05$ \\
\hline
\end{tabular}


Iqbal, et al:: Knowledge of Biological Medicines among Undergraduate Pharmacy Students in India

results have revealed that the pharmacy students have good knowledge about biologic/ biosimilars medicines but the majority of students were looking for authentic sources to get more information about biosimilars/ biologic medicines. Majority of students agree that biological medicines/ biosimilars are not safe. More than sixty percent of pharmacy students believe on biosimilars/biologic medicines don't produce Adverse Drug Reactions. Reason for being not aware of the reporting system of adverse drug reaction could be not having an idea about the general ADR reporting system in India, as well as participants, have don't have an idea about the drug the approval process in India.

Several previous studies have documented a lack of knowledge in pharmacist about biological/biosimilars medicine. ${ }^{15,16}$ Previous research also suggested that biological products should also be included in the curricula of pharmacy graduates. ${ }^{16}$ The students are not well aware of the biosimilars ADR reporting system in India while there is the availability of well-established system of ADR reporting of biosimilars. ${ }^{17}$ India has a systematic procedure of marketing approval of biosimilars ${ }^{18}$ although pharmacy graduates are not aware of the procedure.

This study showed that graduating pharmacy students are keen to see biological being implemented as part of clinical care. Several studies have shown the same level of anticipation among pharmacists having a positive attitude towards biosimilars and willing to incorporate biosimilars into practice. ${ }^{15,16}$ Pharmacy students indicated an absence of biosimilars education during academic years of study, suggesting the need for updating the current curriculum to incorporate biosimilars more comprehensively. The positive perceptions and attitudes demonstrated by this study may indicate that biological medicines have the potential to be implemented by health professionals and pharmacy education in particular. Regardless of the type of educational level and practice setting, all pharmacy students had positive attitudes and perceptions. However, the student's lack of knowledge and confidence highlights the need for targeted education. There is a mixed view of study participants regarding biosimilars and Ayurvedic/Unani medicine similarity in terms of efficacy.

\section{CONCLUSION}

Due to the emergence of biological products and their potential for clinical use, there is need to address the knowledge gap in graduating pharmacy students or future pharmacists and further alterations in the local milieu are required. Such content could be either through professional development courses or through the integration into the curriculum. The survey has drawn out a general agreement that the future pharmacists should be required to have knowledge of biological/ biosimilars in order to be able to recommend biosimilars within their practice, precisely apply the results of biosimilars to drug therapy selection, dosing or monitoring and must be aware of the ethical issues in biosimilar's usages. This will enable pharmacy students to play a dynamic role in shaping the future of biosimilars in India and other developing countries where similar challenges in limited resources and expertise are currently faced.

\section{ACKNOWLEDGEMENT}

All the authors would like to say thanks to all the pharmacy students who respondents on survey questionnaire and participated in the study.

\section{CONFLICT OF INTEREST}

All the authors declared that there is no conflict of interest.

\section{ABBREVIATIONS}

ADR: Adverse Drug Reaction; DNA: Deoxyribonucleic acid; DBT: Department of Biotechnology; WHO: World Health Organization; FDA: The Food and Drug Administration; GEAC: Genetic Engineering Approval Committee; DCGI: Drug Controller General of India.

\section{REFERENCES}

1. Schellekens H. Biosimilar therapeutics-what do we need to consider?. NDT Plus. 2009;2(Suppl 1):i27-36.

2. Mohd AM, Anmol KR, Zeenat I. Biosimilars: Scientific Consideration and Regulatory Frameworks. Current Biotechnology. 2016;5(4):314-24.

3. Leader B, Baca QJ, Golan DE. Protein therapeutics: A summary and pharmacological classification. Nat Rev Drug Discov. 2008;7(1):21-39.

4. Sekhon BS, Saluja V. Biosimilars: An overview. Biosimilars. 2011;1(1):1-11.

5. Leader B, Baca QJ, Golan DE. Protein therapeutics: A summary and pharmacological classification. Nat Rev Drug Discov 2008;7(1):21-39.

6. Schellekens $\mathrm{H}$, Casadevall $\mathrm{N}$. Immunogenicity of recombinant human proteins: Causes and consequences. J Neurol. 2004;251(2):4-9.

7. Haselbeck A. Epoetins: Differences and their relevance to immunogenicity. Curr Med Res Opin. 2003;19(5):430-2.

8. Wadhwa $M$, Thorpe $R$. The challenges of immunogenicity in developing biosimilar products. IDrugs. 2009;12(7):440-4

9. Li J, Yang C, Xia Y, Bertino A, Glaspy J, Roberts M, et al. Thrombocytopenia caused by the development of antibodies to thrombopoietin. Blood. $2001 ; 98(12): 3241-8$

10. The New India Guidelines on Similar Biologics. 2012. Available from: http: // dbtbiosafety.nic.in/DBT2016-17/CDSCO-DBT2016.pdf.

11. Declerck P. Biologicals and biosimilars: A review of the science and its implications. Generics Biosimilars Initiative J. 2012;1(1):13-6.

12. OPPI position paper on 'biosimilar' in India. Available from: http://www. indiaoppi.com/oppibiosimilars.pdf

13. Joshi SR. Biosimilar peptides: Need for pharmacovigilance. J Assoc Physicians India. 2011;59(Suppl):44-7.

14. Hodgson J. WHO guidelines presage US biosimilars legislation?. Nat Biotechnol. 2009;27(11):963-5.

15. Adé A, Bourdon O, Bussières JF. A survey of pharmacists' knowledge and views of biosimilars in Quebec and France. Ann Pharm Fr. 2017;75(4):267-75.

16. Li E, Liu J, Ramchandani M. A Framework for Integrating Biosimilars into the Didactic Core Requirements of a Doctor of Pharmacy Curriculum. Am J Pharm Educ. 2017;81(3):57.

17. Central drug standard control organization (CDSCO). Guidancefor Industry on pharmacovigilance requirements for biological products. 2017;1-15. Available from:http://www.cdsco.nic.in/writereaddata/pharmacovigilanceGuidance.pdf.

18. Central drug standard control organization (CDSCO). Guidelines on Similar Biologic: Regulatory Requirements for Marketing Authorization in India. Availablefrom:http://cdsco.nic.in/writereaddata/Proposed\%20Guidelines\%20 for\%20Similar\%20Biologic\%202016.pdf. 